Куксгауз И.А., Кашкин В.А., Шекунова Е.В., Гущин Я.А., Макаров В.Г., Макарова М.H.

\title{
Изучение терапевтической эфрфективности препарата алфлутоп на модели открытого перелома бедренной кости у крыс
}

ЗАО «Санкт-Петербургский институт фрармации», 188663, Россия, Ленинградская область, Всеволожский район, городской поселок Кузьмоловский, ул. Заводская, д. 3, корпус 245

\begin{abstract}
Введение. Клиническое применение гликозаминогликанов предотвращает разрушение макромолекулярных структур интерстициальной ткани и тканей суставного хряща, стимулирует процессы восстановления и обладает противовоспалительным действием. Эти эффректы синергичны и ведут к активации восстановительных процессов в тканях. Цель исследования - оценка терапевтической эффрективности препарата Алфрлутоп (К.О. Биотехнос С.А., Румыния) на модели открытого перелома бедренной кости у крыс. Методика. В области средней трети диасиза бедренной кости делали 2 расположенных перпендикулярно отверстия диаметром 1 мм, после чего перелом кости осуществляли вручную. Репозицию и фриксацию отломков осуществляли с помощью спиц Киршнера. Препарат (0,2 и 0,45 мл/кг) вводили внутримышечно, начиная с 1-х сут формирования патологии, на протяжении 20 сут. Эффрективность препарата оценивали по особенностям формирования костной мозоли (рентгенологическое исследование) и скорости регенерации костной ткани (гистологическое исследование). Оценку проводили непосредственно после окончания терапии и через 2 нед после ее завершения. Результаты. Показано, что репаративный остеогенез был более выражен у животных, получавших препарат Алфлутоп. На фроне терапии в участке перелома возрастает число случаев перекрытия промежутка костной щели и статистически значимое увеличение площади первичной костной мозоли. При гистологическом исследовании в участке перелома непосредственно после завершения терапии наблюдались признаки формирования хрящевой мозоли, а к исходу 2-й нед костной мозоли с формированием костных балок, т. е. выявляется отчетливая тенденция к активации репаративных процессов. Заключение. Использование препарата Алфлутоп в клинической практике.целесообразно в качестве сопутствующей терапии при переломах костей.
\end{abstract}

Ключевые слова: Алфлутоп; открытый перелом трубчатой кости; крысы.

Для цитирования: Куксгауз И.А., Кашкин В.А., Шекунова Е.В., Гущин Я.А., Макаров В.Г., Макарова М.Н. Изучение терапевтической эффективности препарата алфлутоп на модели открытого перелома бедренной кости у крыс. Патологическая фризиология и экспериментальная терапия. 2020; 64(1): 98-107.

DOI: 10.25557/0031-2991.2020.01.98-107

Для корреспонденции: Кашкин Владимир Александрович, e-mail: kashkinv@gmail.com

Финансирование. Исследование не имело спонсорской поддержки.

Конфликт интересов. Авторы заявляют об отсутствии конорликта интересов.

Поступила 02.10.2019

Принята в печать 16.01.2020

Опубликована 25.02.2020

Kuksgauz I.A., Kashkin V.A., Shekunova E.V., Guschin Ya.A., Makarova M.N., Makarov V.G.

\section{Theurapeutic effects of alflutop in a rat model of femoral fracture}

JSC St. Petersburg Institute of Pharmacy, b. 245, 3, st. Zavodskaya Str. 3, Blvd. 245, Vsevolozhskiy District, Urban-type Settlement Kuzmolovskiy of the Leningrad Region 188663, Russia

Aim. This study was designed to evaluate the therapeutic efficacy of Alflutop (K.O. Biotehnos C.A., Romania) using a rat model of femoral fracture. Methods. In the middle third region of the diaphysis of the femur, two perpendicular holes (diameter, $1 \mathrm{~mm}$ ) were made, and the bone was manually broken. ntramedullary fixation was performed manually using a stainless Kirschner wire. Alflutop ( 0.2 and $0.45 \mathrm{ml} / \mathrm{kg}$, i.m.) was injected into the rats daily for 20 days after the injury. The effect of Alflutop was evaluated immediately at the end of the treatment period and 2 weeks after the treatment completion using X-ray (callus formation) and histological data (bone regeneration). Results. The therapy resulted in some cases in partial bone fusion in the fracture line and significantly increased the area of cartilage callus. The most pronounced therapeutic effect was observed on day 35 of the experiment. Histological examination revealed signs of fracture healing in all experimental groups. Immediately after the therapy period, the formation of cartilage callus was observed in the fracture line. In 2 weeks after the therapy, signs of the formation of mineralized callus were noted. Along with the cartilaginous tissue, which was widely present, formation of trabecular bone and bone beams was observed. Two weeks after the therapy completion, the fracture healing process was more intensive in animals 
treated with Alflutop in either dose. Conclusion. The study confirmed that Alflutop can be used as a concomitant therapy for fracture healing in clinical practice.

Keywords: Alflutop; bone femur fracture; rat.

For citation: Kuksgauz I.A., Kashkin V.A., Shekunova E.V., Guschin Ya.A., Makarova M.N., Makarov V.G. Alflutop theurapeutic effects in the rat femoral fracture model. Patologicheskaya Fiziologiya i Eksperimental naya terapiya. (Pathological Physiology and Experimental Therapy, Russian Journal). 2020; 64(1): 98-107. (in Russian).

DOI: 10.25557/0031-2991.2020.01.

For correspondence: Kashkin V.A., Candidat of Medical Sciences, Senior researcher, department of experimental pharmacology, e-mail: kashkinv@gmail.com

Conflict of interest. The authors declare no conflict of interest.

Acknowledgments. The study had no sponsorship.

Information about authors:

Kashkin V.A., https://orcid.org/0000-0002-7202-0233

Makarova M.N., https://orcid.org/0000-0003-3176-6386

Makarov V.G., https://orcid.org/0000-0002-2447-7888

Received 02.10.2019

Accepted 16.01.2020

Published 25.02.2020

\section{Введение}

Алфлутоп - хондропротектор, активным компонентом которого является биоактивный концентрат из мелкой морской рыбы. Концентрат содержит гликозаминогликаны, в т.ч. хондроитин-4 и 6-сульфат, дерматансульфат, кератансульфат; глюкуроновую кислоту, аминокислоты, миоинозитол фосфаты и низкомолекулярные полипептиды. Алфлутоп обладает противовоспалительным действием, предотвращает разрушение макромолекулярных структур нормальных тканей, стимулирует процессы восстановления в интерстициальной ткани и ткани суставного хряща, что объясняет его обезболивающее действие. Оба эти эффекта синергичны и обуславливают активацию восстановительных процессов в тканях (в частности, восстановление структуры хряща) [1].

Протеогликаны кости представлены в основном хондроитин сульфатом, который очень важен для обмена веществ костной ткани. Он образует с белками основное вещество кости и важен в обмене $\mathrm{Ca}^{2+}$. Хондроитин сульфат в условиях стабильной фиксации длинных трубчатых костей приводит к улучшению кровоснабжения костной ткани в зоне перелома, что способствует адекватному образованию костной мозоли и в целом значительно сокращает сроки лечения и реабилитации больных [2]. В костной ткани также присутствует гиалуроновая кислота, которая играет важную роль в морфогенезе. [3].

Фармакологическое действие препарата Алфлутоп определяется не только как хондропротективное, но и как противовоспалительное, анальгезирующее, стимулирующее регенерацию тканей действие. В основе этих эффектов лежит способность компонентов препарата подавлять активность гиалуронидазы и нормализовать биосинтез гиалуроновой кислоты [4]. Другой механизм противовоспа- лительного действия препарата Алфлутоп заключается в блокаде высвобождения интерлейкинов ИЛ-6 и ИЛ-8, основных модуляторов прогрессирования острой фазы воспаления в хондроцитах у человека [5]. Все это дает основание рассматривать препарат Алфлутоп в качестве лекарственного средства, ускоряющего регенерацию костной ткани при переломе.

Исследованию хондроитин сульфата, входящего в состав тестируемого препарата, посвящен ряд клинических исследований, где была доказана эффективность хондроитин сульфата только при лечении остеоартроза коленных и тазобедренных суставов со степенью доказательности А (EULAR, Европейская противоревматическая лига). В тоже время, в комплексной терапии переломов двойных слепых, плацебо контролируемых исследований не проводилось [6]. Однако, принимая во внимание взаимосвязь механизмов регенерации хрящевой ткани суставов и костной ткани, можно предполагать, что хондроитин сульфат будет эффективен и при лечении переломов кости.

Была выбрана методика открытой поперечной остеотомии средней трети бедра у крыс, поскольку открытый перелом конечностей является часто встречающейся травмой, лечение больных сложное и длительное, наблюдается высокая частота гнойно-некротических осложнений, формирование ложных суставов и посттравматических дефектов тканей $[7,8]$. При множественной и сочетанной травме особенно высока частота нарушений консолидации переломов $[9,10]$. Поэтому в настоящее время проблема поиска путей нормализации механизмов регенерации открытых переломов крайне актуальна. Для решения данной проблемы и трансляционного переноса экспериментальных данных в клиническую область применения тестируемого 
препарата Алфлутоп нами было проведено моделирование перелома бедренной кости по открытому типу. Данный метод формирования патологии широко используется в экспериментальных исследованиях, например, при изучении влияния препаратов на эффективность консолидации переломов при остеопорозе [11], репаративного гистогенеза костной ткани на фоне применения препарата «Винфар» [12], или на фоне использования метаболитов bacillus subtilis 804, содержащих фактор роста фибробластов [13]. Применение модели остеотомии по открытому типу часто востребовано для изучения влияния различных антибактериальных препаратов на скорость репаративных процессов в костной ткани $[14,15]$.

Также известно, что нестабильность в месте перелома на стадии репарации стимулирует более активное образование наружной мозоли. Эти микродвижения активируют созревание мозоли и ее трансформацию из хрящевой в более твердую костную ткань [16], что нашло продолжение в разработке метода лечения открытого перелома кости при помощи механической стимуляции с использованием внешних фиксаторов [17].

Цель исследования - оценка терапевтической эффективности препарата Алфлутоп на модели перелома бедренной кости у крыс.

\section{Методика}

Эксперименты выполнены на самцах аутбредных крыс массой 220-260 г (питомник АО «НПО «ДОМ ФАРМАЦИИ», Россия). Животных содержали в условиях 24-хчасового фоторежима (12 ч день: 12 ч ночь, включение

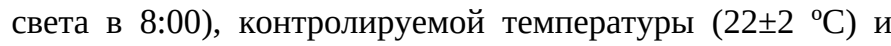
влажности $(65 \pm 10 \%)$ воздуха при свободном доступе к очищенной воде и стандартному корму (гранулированный комбикорм). За неделю до начала эксперимента животные были рассажены в клетки индивидуального содержания.

Исследование выполнено в соответствии с рекомендациями Директивы 2010/63/EU Европейского парламента и совета Европейского Союза от 22 сентября 2010 года по охране животных. Исследование соответствовало принципам 3 « $\mathrm{R}$ (reduction, refinement and replacement). Работа была одобрена биоэтической комиссии АО «НПО «ДОМ ФАРМАЦИИ»», протокол № 2.74/18.

Моделирование патологическооо процесса. Для моделирования экспериментальной патологии использовали общую анестезию смесью препаратов Zoletil 100 («Virbac Sante Animale», Франция) и Xila («Interchemie werken «De Adelaar» B.V», Нидерланды) (20 мг/мл, 1:1; 50 мкл на крысу массой 250 г), внутримышечно (в/м).
Моделирование открытого перелома бедренной кости осуществляли на правой тазовой конечности крыс при соблюдении правил асептики и антисептики. После подготовки операционного поля в области латеральной поверхности правого бедра делали продольный разрез кожи приблизительно 1,5 см в длину. Бедренную кость выделяли с двух сторон путем тупого препарирования $m$. biceps femoris. В области средней трети диафиза бедренной кости перпендикулярно оси делали 2 отверстия диаметром 1 мм, после чего перелом кости осуществляли вручную. Репозицию и фиксацию отломков осуществляли открытым ручным способом. Для этого подбирали часть спицы Киршнера, которая соответствовала диаметру интрамедуллярного просвета бедренной кости (1,2; 1,5 или 1,8 мм). Кость фиксировали на спице путем ручного погружения подобранной спицы в обе части интрамедуллярного пространства [18]. Таким образом, в эксперименте воспроизводили открытый инвазивный вид остеосинтеза, обеспечивающий прямое сращение перелома. Рану послойно ушивали, после чего обрабатывали антисептиком. В послеоперационный период животным внутримышечно вводили Кетонал в дозе 5 мг/кг, однократно [19].

Препараты,испольхзованные для терапии. В исследовании использовали препарат Алфлутоп, в лекарственной форме раствор для инъекций, серия 3360418 (К.О. Биотехнос С.А., Румыния). Контрольные животные получали физиологический раствор.

Дизайн исследования. В эксперимент включены 3 группы по 12 крыс в каждой. Открытый перелом воспроизводили у всех животных. Терапию начинали непосредственно после проведения операции по моделированию перелома. Животные 1-й группы (контроль) получали физиологический раствор в объеме 0,45 мл/кг. Животные 2-й и 3-й групп - раствор готовой лекарственной формы Алфлутопа в дозах 0,2 мл/кг и 0,45 мл/кг соответственно. Курс терапии составил 20 сут. Алфлутоп или физиологический раствор вводили ежедневно, один раз в сут, в/м в мышцы бедра левой тазовой конечности. Эвтаназию проводили с помощью $\mathrm{CO}_{2}$-камеры, в условиях постепенного заполнения камеры диоксидом углерода: на 21-е сут (50\% крыс из каждой группы) и на 35-е сут (оставшиеся животные).

Рентгенологическое исследование. После эвтаназии у каждого животного ампутировали правую конечность на уровне тазобедренного сустава и проведили рентгенологическое исследование места перелома с помощью установки (Orange - 1040HF; EcoRay Co., Ltd, Сеул, Южная Корея) с параметрами экспозиции: 1,25 mАс и анодного 
напряжения: 41 кВ. По результатам рентгенологического исследования производили расчет площади костной мозоли. Площадь (мм²) видимого участка периостальной части костной мозоли (регенерата) измеряли путем ввода изображений в программу «ImageJ» вер.1,52i (NIH, Bethesda, $\mathrm{MD)}$ и визуализации любого участка костной мозоли, видимого за исходной поверхностью периостальной части кости.

Стадию заживления перелома на каждом этапе определяли с использованием 4-балльной системы оценки рентгенограмм методом S.J. Warden и соавт. [20]: 0 - отсутствие признаков заживления; 1 - образование костной мозоли без перекрытия линии перелома; 2 - образование костной мозоли с возможным перекрытием линии перелома; 3 - полное закрытие линии перелома.

Контраст изображения был изменен для облегчения разграничения исходной периостальной поверхности для мозолей с повышенной непрозрачностью. Двум исследователям, осуществлявшим анализ рентгенологических снимков независимо друг от друга, не было известно о принадлежности животного к определенной экспериментальной группе.

Гистологическое исследование. Материал (бедренную кость) фиксировали в 10\% нейтральном растворе формалина, декальцинировали в растворе на основе муравьиной и соляной кислот, обезвоживали и пропитывали парафином. Срезы толщиной 5-7 мкм окрашивали гематоксилином и эозином. Гистологические препараты просматривали при увеличении х100 (микроскоп Accu-Scope 3000 SERIES, США). Микрофотографирование проводили при помощи цифровой фотокамеры TOUPCAM UCMOS05100KРА и программного обеспечения ToupView 3.7.7892 (Китай).

Полуколичественный анализ проводили с учетом факторов, влияющих на регенерацию кости:

1) воспалительный инфильтрат: 0 - отсутствует; 1 слабо выражен; 2 -умеренно выражен; 3 - отчетливо выражен.

2) коллагеновые волокна и признаки формирования новой кости: 0 - отсутствуют; 1 - слабо выражены; 2 - умеренно выражены; 3 -отчетливо выражены.

3) восстановление кортикальной пластинки: 0 - отсутствует; 1 - нечеткий контур краев; 2 - покрыто около 50\% ширины фрагмента; 3 - покрыто более 50\% ширины фрагмента.
Результаты оценивали по сумме баллов всех признаков в каждой группе [21].

Статистическая обработка. Для оценки данных с признаками нормального распределения был использован дисперсионный анализ (ANOVA) с последующим межгрупповым сравнением с применением критерия Тьюки. Для сравнения 2-х групп использовали t-тест. Для данных, не подчиняющихся закону нормального распределения, применяли критерий Краскела-Уоллиса. Различия были определены при 0,05 уровне значимости. Статистический анализ выполнялся с помощью программного обеспечения Statistica 10.0. (StatSoft, США).

\section{Результаты}

Результаты рентгенологического исследования. На 35-е сут после моделирования патологии в группах, получавших Алфлутоп, в отличие от контрольной группы, в единичных случаях были отмечены участки сращения перелома, несмотря на отсутствие статистически значимых отличий (рис. 1).

Следует отметить, что непараметрический анализ данных показал отсутствие статистически значимого влияния препарата на процесс заживления перелома по результатам полуколичественной оценки по методу $\mathrm{S}$. Warden и соавт. 2009 [20] ( $p>0,05$, критерий Краскела-Уоллиса, табл. 1).

В ходе эксперимента обнаружена тенденция к усилению репаративных процессов.

Проведение однофакторного дисперсионного анализа показало влияние фактора «группа» на площадь костной мозоли на 35-е сут эксперимента ( $p=0,009$, ANOVA). При последующем межгрупповом сравнении установлено увеличение площади костной мозоли в группах, получавших тестируемый препарат в дозах 0,2 и 0,45 мл/кг (рис. 2) по сравнению с показателем в контрольной группе. Статистически значимого отличия на 21-е сут эксперимента между экспериментальными группами по сравнению с контрольной группой не обнаружено (рис. 2).

Таким образом, анализ рентгенологических снимков показал, что в группах животных, получавших терапию тестируемым препаратом, по сравнению с группой контроля наблюдали увеличение случаев перекрытия промежутка костной щели, увеличение площади первичной костной мозоли. Терапевтический эффект препарата достиг статистической значимости на 35-е сут после индукции патологии. 


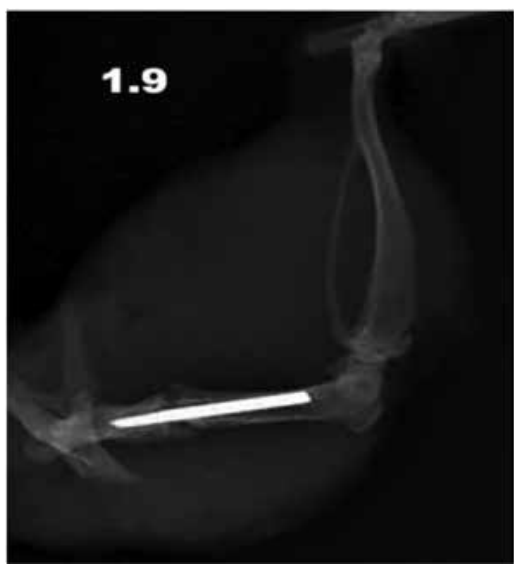

A

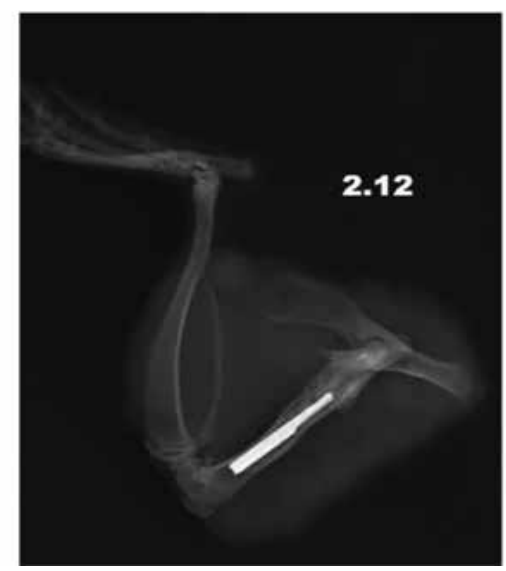

Б

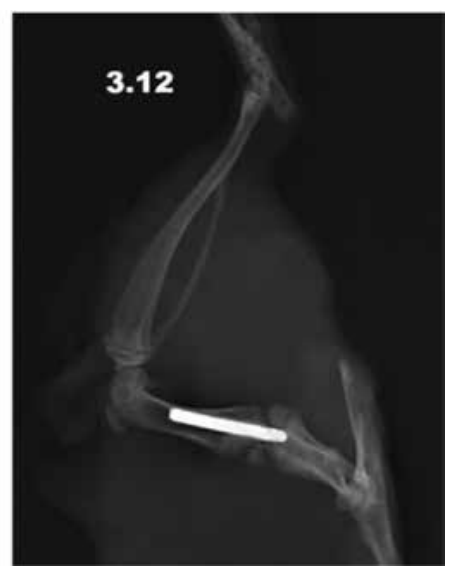

B

Рис. 1. Рентгенограмма (боковая проекция) правой тазовой конечности крыс контрольной группы (А), групп, получавших препарат Алфлутоп в дозах 0,2 мл/кг (Б) и 0,45 мл/кг (В). 35-е сут эксперимента

Таблица 1 ционной ткани, богатой сосудами, хрящевой ткани и не-

Влияние препарата Алфлутоп на процесс сращения костной ткани, баллы, Me (Q1:Q3), $n=6$

\begin{tabular}{|l|l|l|l|}
\hline \multirow{2}{*}{ Группа } & \multirow{2}{*}{$\begin{array}{l}\text { Доза препарата } \\
\text { мл/кг }\end{array}$} & \multicolumn{2}{|l|}{ День эксперимента } \\
\cline { 3 - 4 } & 21-е сут & 35-е сут \\
\hline \multirow{2}{*}{ Контрольная } & 0 & $1,0(0,0 ; 1,0)$ & $1,5(1,0 ; 2,0)$ \\
\hline \multirow{2}{*}{ Алфлутоп } & 0,2 & $1,0(0,0 ; 1,0)$ & $2,0(1,0 ; 3,0)$ \\
\cline { 2 - 4 } & 0,45 & $1,0(1,0 ; 2,0)$ & $2,0(1,0 ; 2,0)$ \\
\hline
\end{tabular}

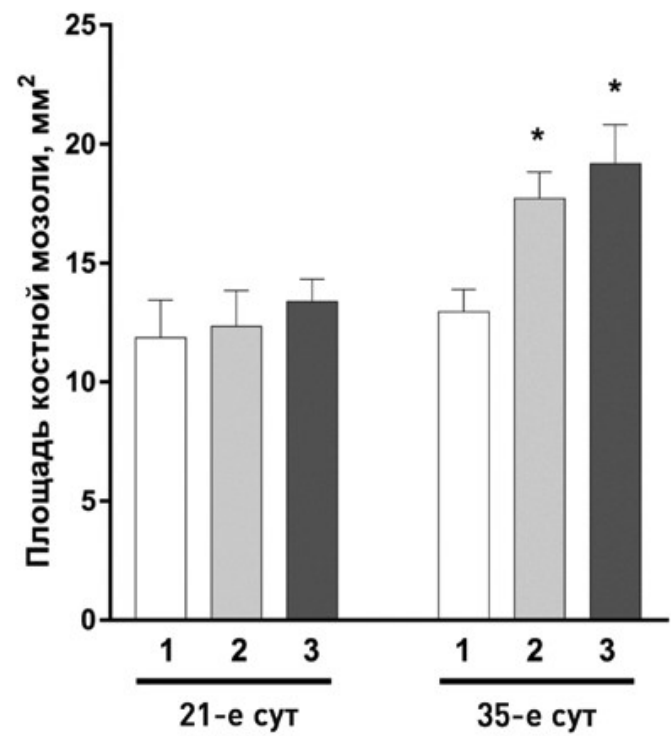

Рис. 2. Влияние препарата Алфлутоп на площадь костной мозоли.

По оси ординат - площадь костной мозоли в мм². По оси абсцисс - экспериментальные группы. 1 - контрольная группа; 2 - Алфлутоп в дозе 0,2 мл/кг; 3 - Алфлутоп в дозе 0,45 мл/кг; * $-p<0,05$, статистически значимые отличия от контрольной группы (критерий Тьюки).

Результаты гистологического исследования. На 21-е сут эксперимента в месте перелома во всех экспериментальных группах наблюдали образование первичной костной мозоли, заполняющей дефект и состоящей из гранулябольших очагов остеогенной грубоволокнистой соединительной ткани. Хрящевые тяжи проникали в центральную - интрамедиарную зону. Наблюдалась пролиферация остеобластов в зоне перелома, что указывает на процесс формирования хрящевой мозоли. Небольшие участки воспалительной лимфоцитарной инфильтрации и кровоизлияния располагались в периостальной и в интрамедиарной зонах. K 35-м сут в месте перелома отмечалось заполнение дефекта небольшими полями костной ретикулофиброзной и преимущественно хрящевой ткани с крупными хондроцитами и признаками деградации (рис. 3, А). В дистальных отделах наблюдали формирование грубоволокнистых костных балок без обызвествления с большим количеством остеобластов и некоторым количеством замурованных остеоцитов (рис. 3, Б). Между трабекулами пространство было заполнено гемопоэтической тканью (рис. 3, В). На 35-е сут у животных всех групп был завершен процесс образования хрящевой мозоли и наблюдался этап замещения ее на костную (рис. 3 , Г).

При анализе данных (критерий Краскела-Уоллиса) влияния фактора «группа» на исследуемые показатели ни на 21-е, ни на 35-е сут эксперимента значимых различий между группами не установлено (табл. 2).

На 35-е сут эксперимента отмечена тенденция к увеличению выраженности репаративных изменений в месте перелома у крыс, получавших тестируемый препарат в дозах 0,2 мл/кг и 0,45 мл/кг (табл. 2), что было статистически незначимо. Восстановление кортикальной пластинки имело место у 50\% животных, получавших Алфлутоп в максимальной дозе, тогда как в контрольной группе данный признак был обнаружен только в 1 случае. 
A

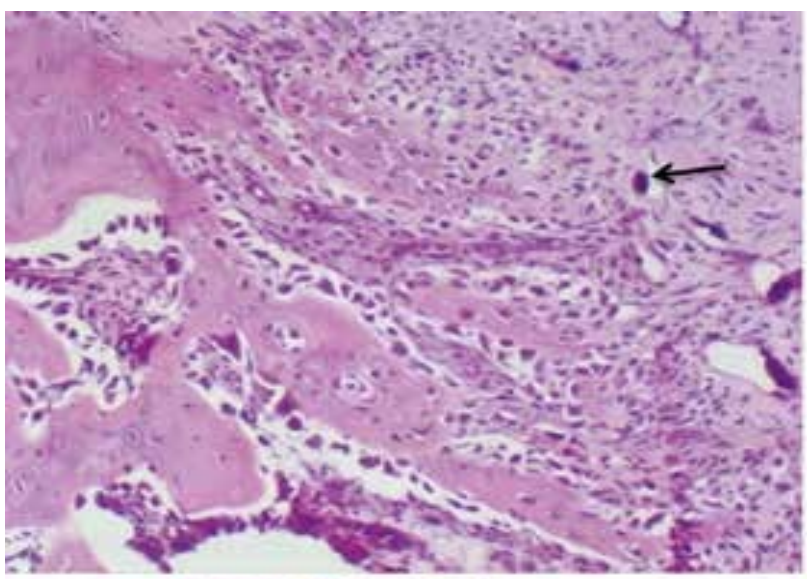

B

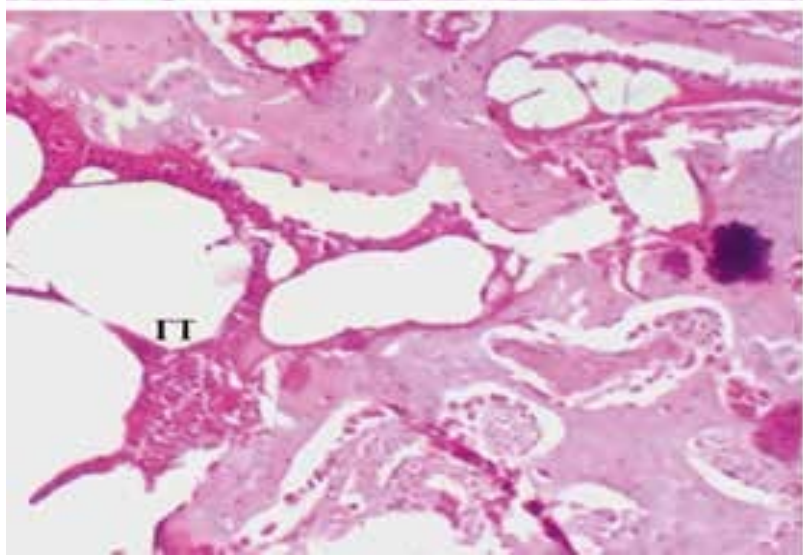

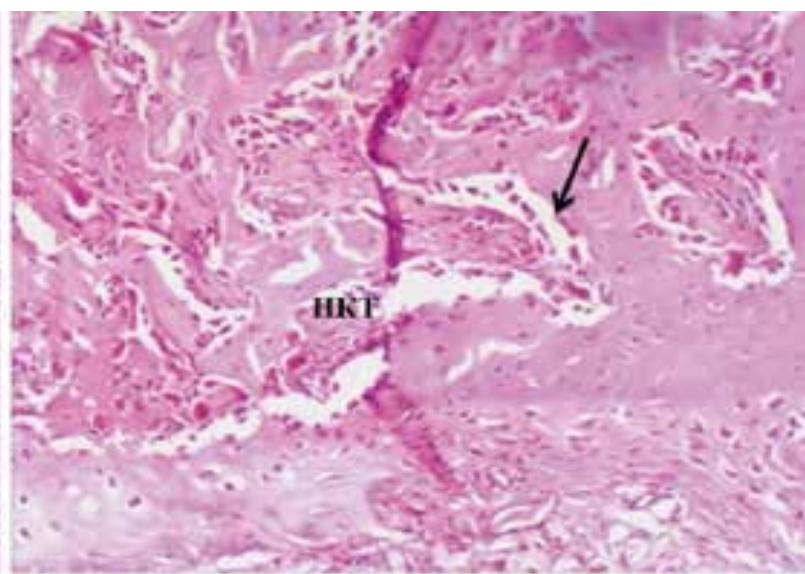

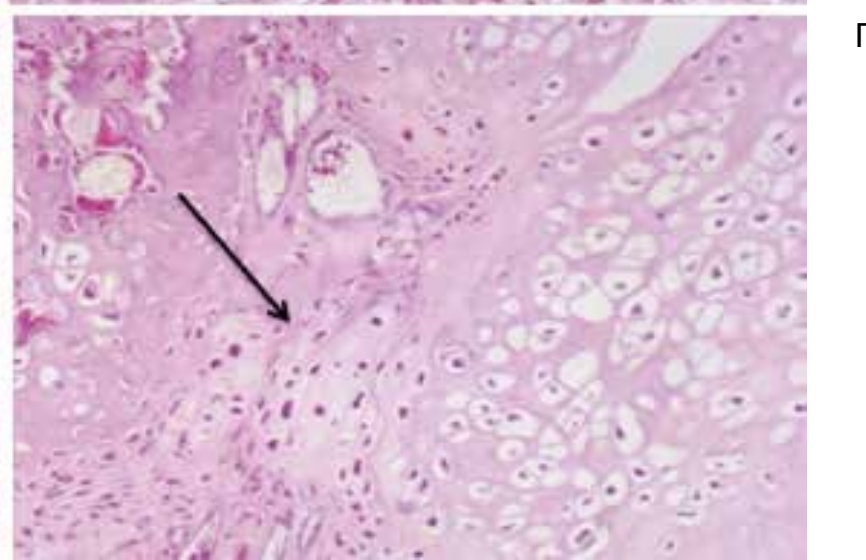

Рис. 3. Срез бедренной кости. Ув. ×100. Окраска гемотоксилин-эозин.

А - Эндостальная костная мозоль (стрелка) заполняет пространство между костными балками; Б - Формирование новых костных балок (НКТ), большое количество остеобластов (стрелка); В - Формирование новых костных балок, между которыми обнаруживается гемопоэтическая ткань (ГТ); г - Замещение хрящевой ткани костной, (стрелка).

Полуколичественная оценка выраженности репаративных изменений (сумма баллов, $n=6)$

\begin{tabular}{|c|c|c|c|c|}
\hline \multirow[b]{2}{*}{ Группа } & \multirow{2}{*}{$\begin{array}{l}\text { Доза препа- } \\
\text { рата мл/кг }\end{array}$} & \multicolumn{3}{|c|}{ Оцениваемые показатели } \\
\hline & & $\begin{array}{l}\text { Выраженность воспа- } \\
\text { ления }\end{array}$ & $\begin{array}{l}\text { Коллагеновые волокна, фор- } \\
\text { мирование новой кости }\end{array}$ & $\begin{array}{l}\text { Восстановление корти- } \\
\text { кальной пластинки }\end{array}$ \\
\hline \multicolumn{5}{|c|}{ 21-е сут эксперимента } \\
\hline Контрольная & 0 & 14 & 8 & 1 \\
\hline \multirow{2}{*}{ Алфлутоп } & 0,2 & 12 & 9 & 0 \\
\hline & 0,45 & 15 & 9 & 1 \\
\hline \multicolumn{5}{|c|}{ 35-е сут эксперимента } \\
\hline Контрольная & 0 & 7 & 14 & 1 \\
\hline \multirow{2}{*}{ Алфлутоп } & 0,2 & 9 & 13 & 2 \\
\hline & 0,45 & 9 & 14 & 3 \\
\hline
\end{tabular}

\section{Обсуждение}

Таким образом, по результатам гистологического исследования во всех группах имело место заживление костного дефекта. На 35-е сут отмечена тенденция к усилению репаративных процессов в месте перелома у жи- вотных, получавших Алфлутоп в дозах 0,2 мл/кг и 0,45 Мл/кг.

Анализ рентгенологических снимков показал, что репаративный остеогенез был более выражен у животных, получавших Алфлутоп, по сравнению с группой контроля. На фоне терапии в участке перелома наблюда- 
ли увеличение количества случаев перекрытия промежутка костной щели, значимое увеличение площади первичной костной мозоли. Наиболее выраженный терапевтический эффект отмечался на 35-е сут после моделирования перелома. В ходе гистологического исследования во всех группах отмечены признаки заживления костного дефекта. На 21-е сут в месте перелома обнаружены отчетливые признаки формирования хрящевой мозоли. К 35-м сут наблюдалась стадия формирования костной мозоли. Хрящевая ткань по-прежнему сохранялась на значительной площади, но при этом наблюдалось образование губчатой костной ткани с формированием костных балок. К 35-м сут эксперимента проявлялась тенденция к усилению репаративных изменений в месте перелома у животных, получавших Афлутоп в дозах 0,2 мл/кг и 0,45 мл/кг.

По данным литературы к 35-м сут после индукции перелома может наблюдаться оссификация первичной костной мозоли с редукцией её площади и наличием участков полного сращения перелома [20]. В основном, такая динамика процесса характерна для моделей, при которых перелом кости формируется по «закрытому» типу, при этом полная консолидация перелома наблюдается лишь к 56-м сут [20]. В проведенном исследовании к 35-м сут полная консолидация костного дефекта не происходлиа, что обусловлено особенностью моделирования перелома кости (по «открытому» типу) [18]. При таком способе моделирования перелома формируется повреждение костной ткани максимальной степени, а также отсутствует возможность полной иммобилизации конечности животного. При этом процесс заживления перелома происходит по вторичному, или непрямому типу репаративной регенерации (усиленной физиологической регенерации). В клинической практике он наблюдается при лечении переломов длинных трубчатых костей, когда полностью обездвижить костные отломки невозможно, или в случаях недостаточной иммобилизации конечности гипсовой повязкой. В таких случаях на второй стадии заживления перелома отмечается гипертрофия периостальной костной мозоли, а между отломками процесс заживления начинается с образования хрящевой ткани. Только при обездвиживании зоны перелома хрящевая интермедиарная мозоль рассасывается за счет периоста и эндоста и замещается костной. Таким образом, при вторичном типе заживления значительно удлиняется вторая стадия образования костной мозоли. Поскольку полностью иммобилизовать конечность крысы невозможно, животное начинает опираться на нее достаточно быстро (уже на 34-й сут после операции), наблюдается замедленная консо- лидация перелома, которая характеризуется задержкой перехода хрящевой мозоли в костную. На рентгенограмме сохраняется линия перелома и слабые признаки вторичной костной мозоли [22]. При переломе бедренной кости у крыс по «открытому» типу даже на 61-е сут эксперимента интермедиарная костная мозоль может быть представлена разросшейся ретикулофиброзной костной тканью с очагами деградирующего гиалинового хряща и немногочисленными костномозговыми полостями без признаков формирования костномозгового канала [12, 23].

В проведенном исследовании к 35-м сут отмечено усиление образования хрящевой мозоли в группах, получавших Алфлутоп. Это может быть обусловлено стимулирующим действием препарата на хондрогенез, которое было доказано в экспериментах in vitro [5, 24], а также рядом клинических исследований, где Алфлутоп использовали у пациентов с остеоартрозом [4, 25]. Особенностью фармакодинамического профиля Алфлутопа является его способность предотвращать разрушение макромолекулярных структур нормальных тканей, стимулировать процессы восстановления в интерстициальной ткани и суставном хряще. Стоит отметить, что на фоне применения высокомолекулярной гиалуроновой кислоты на модели дефекта бедренной кости у крыс было показано ее стимулирующее влияние на формирование кости, обусловленное стимуляцией дифференциации мезенхимальных клеток в области дефекта [26].

Механизм действия препарата Алфлутоп опосредован фармакологической активностью компонентов, входящих в его состав, а именно хондроитина сульфата, который, являясь полимерным сульфатированным гликозаминогликаном, обладает тропностью к хрящевой ткани, инициирует фиксацию серы в процессе синтеза хондроитин-серной кислоты, что, в свою очередь, способствует отложению кальция в костях, замедляет резорбцию костной ткани и снижает потерю $\mathrm{Ca}^{2+}$. Улучшается также фосфорно-кальциевый обмен в хрящевой ткани, ускоряются процессы ее восстановления, задерживаются процессы дегенерации хрящевой и соединительной ткани. Известно, что гликозаминогликаны взаимодействуют с остеоцитами, остеобластами и остеокластами напрямую через интегриновые рецепторы [27] или через другие специфические рецепторы поверхности клеток [28], оказывая тем самым прямое и косвенное влияние на рост, миграцию, дифференцировку и адгезию этих клеток.

Положительное влияние хондроитин сульфата на формирование костной ткани было подтверждено в ряде 
исследований с использованием различных экспериментальных моделей при остеотомии по открытому типу на мелких и крупных животных [29]. Также хондроитина сульфат способен усилению взаимодействия спицы Киршнера, или любого другого импланта, с клетками костной ткани, так как он является посредником для связывания остеобластов и остеокластов с внеклеточной матрицей кости и способствует привлечению в места контактов с имплантом различных медиаторов, таких как, факторы роста и цитокины [30]. Поэтому терапия переломов костей препаратами, содержащими хондроитин сульфат, такими как Алфлутоп, приводит к формированию благоприятной среды для остеобластов, в результате улучшается заживление костей вокруг металлических имплантатов путем создания искусственной внеклеточной матрицы на них. В экспериментах in vitro и in vivo было показано, что адсорбционная иммобилизация коллагена и хондроитин сульфата на поверхностях из титана является биологически стабильной и усиливает остеобластную пролиферацию [31] не провоцируя при этом длительных воспалительных или иммунных реакций [32].

Таким образом, в анаболическую фазу после перелома кости, хондроитина сульфат, который является основным компонентом препарата Алфлутоп, активирует анаболические процессы и подавляет катаболические, в которых участвуют металлопротеиназы -3,-9,-13, катепсин $\mathrm{B}$, лейкоцитарная эластаза, улучшает микроциркуляцию в субхондральной кости и синовиальной ткани, а также подавляет апоптоз хондроцитов, ингибирует индуцируемую нуклеотидной транслокацией NFkB [33].

Стоит заметить, что эффективность раннего начала введения Алфлутопа согласуется с данными литературными, где было показано, что ведение хондроитина сульфата начиная с первого дня, способствует более ранней активации клеток хрящевой ткани. Это в свою очередь позволяет ускорить формирование фиброзно-хрящевой мозоли и обеспечить более ранние сроки начала ее минерализации, что, в итоге, способствует более быстрому формированию костной мозоли при переломах и трещинах [34].

\section{Заключение}

Таким образом, Алфлутоп, являясь комплексным препаратом, в состав которого входят высокомолекулярные сульфатированные гликозаминогликаны и глюкуроновая кислота, стимулирует хондрогенез с последующей оссификацией костной мозоли и репарацией повреждения, что позволяет рассматривать препарат в качестве средства терапии при переломах костей. В целом, полученные к 35-м сут после моделирования патологии результаты говорят об интенсификации процессов консолидации перелома бедренной кости у животных, получавших в течение 20-ти сут терапию препаратом Алфлутоп в дозах 0,2 мл/кг и 0,45 мл/кг. Данные свидетельствуют о возможности применения препарата в качестве сопутствующей терапии при переломах костей различной степени тяжести.

\section{Участие авторов:}

Концепция и дизайн исследования - Куксгауз И.А., Кашкин В.А., Шекунова Е.В.

Сбор и обработка материала - Куксгауз И.А., Кашкин В.А., Шекунова Е.В., Гущин Я.А.

Статистическая обработка - Куксгауз И.А., Кашкин В.А., Шекунова Е.В.

Написания текста - Куксгауз И.А., Кашкин В.А., Шекунова Е.В.

Редактирование - Макаров В.Г., Макарова М.Н.

\section{Литература}

1. Алфлутоп (Alflutop ${ }^{\circledR}$ ). Available at: https://grls.rosminzdrav.ru/ Grls View v2.aspx?routingGuid=e8ad7e7f-98c1-4389-a6d61fc8c4cd969a\&t.

2. Волошин В.П., Сараванан С.А., Еремин А.В. и др. Исследование эффективности действия препарата хондрогард (хондроитина сульфат) у пациентов с переломами различной локализации. Фарматека. 2016; 7: 76-9

3. Вавилова Т.П. Биохимия тканей и жидкостей полостей рта: учебное пособие. Глава 5. Биохимия костной ткани 2-е изд., испр. и доп.; М.; ГЭОТАР-Медиа; 2008.

4. Пешехонова Л.К., Красюков П.А., Пешехонов Д.В. Оценка роли Алфлутопа в терапии остеоартроза: показания, клиническая эффективность, переносимость и влияние на качество жизни. Медицинский совет. 2016; 11: 100-4.

5. Olariu L, Pyatigorskaya N, Dumitriu B, Manuela D, Pavlov A, Rosoiu N. Alflutop ${ }^{\circledR}$ modulates “in vitro" relevant mechanisms of osteoarthritic pathology. Academy of Romanian ScientistsAnnals Series on BiologicalSciences. 2017; 6(1): 82-99.

6. McAlindon T.E., LaValley M.P., Gulin J.P., Felson D.T. Glucosamine and chondroitin for treatment of osteoarthritis: a systematic quality assessment and meta-analysis. Jama. 2000; 283(11): 1469-75.

7. Мартель И.И. Чрескостный остеосинтез по Илизарову в комплексном лечении больных с открытыми повреждениями конечностей. Гений ортопедии. 2011; 2: 44-8.

8. Мироманов А.М., Герасимов А.А., Намоконов Е.В., Мироманова Н.А. Прогнозирование гнойно-воспалительных осложнений при открытых переломах длинных трубчатых костей. Вестник хирургии им. И.И. Грекова. 2009; 168(3): 57-60.

9. Ключевский В.В., Соловьёв И.Н., Литвинов И.И., Тимушев А.А. Лечение открытых переломов голени. Врач-аспирант. 2015; 68(1.1): 199-203.

10. Кавалерский Г.М., Петров Н.В., Бровкин С.В., Смирнов А.Е., Калашник А.Д., Карев А.С. и др. К вопросу о лечении открытых переломов голени. Московский хирургический журнал. 2014; 6: 33-6.

11. Mathavan N., Tägil M., Isaksson H. Do osteoporotic fractures constitute a greater recalcitrant challenge for skeletal regeneration? Investigating the efficacy of BMP-7 and zoledronate treatment of diaphyseal fractures in an open fracture osteoporotic rat model. Osteoporosis international: a journal established as result of cooperation between the European Foundation for 
Osteoporosis and the National Osteoporosis Foundation of the USA. 2017; 28(2): 697-707.

12. Миханов В.А., Полякова В.С., Копылов В.А., Мхитарян Е.Е. Репаративный гистогенез костной ткани в условиях открытого перелома диафиза длинной трубчатой кости у крыс при использовании препарата «ВИНФАР». Современные проблемы науки и образования. 2015; 3: 162 .

13. Копылов В.А., Сафронов А.А., Захаров В.В. Стимуляция репаративного остеогенеза при лечении открытых переломов с помощью метаболитов bacillus subtilis 804, содержащих фактор роста фибробластов. Wschodnioeuropejskie Czasopismo Naukowe (East European Scientific Journal). 2016; 9: 72-9.

14. Penn-Barwell J.G., Baker B., Wenke J.C. Local bismuth thiols potentiate antibiotics and reduce infection in a contaminated open fracture model. $J$ Orthop Trauma. 2015; 29(2): e73-8.

15. Mills R., Cheng T.L., Mikulec K., Peacock L., Isaacs D., Genberg C., et al. CSA-90 Promotes Bone Formation and Mitigates Methicillin-resistant Staphylococcus aureus Infection in a Rat Open Fracture Model. Clinical orthopaedics and related research. 2018; 476(6): 1311-23.

16. Frost H. M. The biology of fracture healing. An overview for clinicians. Part I. Clin Orthop Relat Res. 1989; 248: 283-93.

17. Currey J.A., Mancuso M., Kalikoff S., Miller E., Day S. Controlled cyclic compression of an open tibial fracture using an external fixator affects fracture healing in mice. J Biomech Eng. 2015; 137(5): 051011.

18. Metineren H, Dulgeroglu TC, Metineren MH, Aydin E. Effect of nebivolol on fracture healing: An experimental rat model. Advances in clinical and experimental medicine: official organ Wroclaw Medical University. 2017; 26(6): 919-23.

19. Anesthesia and Analgesia in Laboratory Animals at UCSF. The Regents of the University of California. Available at: http://www.iacuc.ucsf.edu/Proc/ awRbtFrm.asp.

20. Warden SJ, Komatsu DE, Rydberg J, Bond JL, Hassett SM. Recombinant human parathyroid hormone (PTH 1-34) and low-intensity pulsed ultrasound have contrasting additive effects during fracture healing. Bone. 2009; 44(3): 485-94.

21. Магрупов Б.А., Шадманов Т.Т., Ташпулатов А.А., Ходжаев Р.Р., Валиев Э.Ю. Реакция костной ткани на некоторые имплантаты в эксперименте. Морфологія. 2012; VI(2): 19-28.

22. Волотовский А.И., Макаревич Е.Р., Чирак В.Э. Регенерация костной ткани в норме и при патологии: метод. рекомендации. Минск БГМУ; 2010.

23. Garcia P, Histing T, Holstein $\mathrm{JH}$, et al. Rodent animal models of delayed bone healing and non-union formation: a comprehensive review. European cells \& materials. 2013; 26: 1-12; discussion 12-14.

24. Olariu L, Pyatigorskaya N, Dumitriu B. "In vitro" chondro-restitutive capacity of Alflutop ${ }^{\circledR}$ proved on chondrocytes cultures. Romanian Biotechnological Letters. 2016; 22(6): 12047-53.

25. Чичасова Н.В. Современная терапия остеоартроза. Медицинский совет. 2017; 17: 138-45.

26. Sasaki T, Watanabe C. Stimulation of osteoinduction in bone wound healing by high-molecular hyaluronic acid. Bone. 1995; 16(1): 9-15.

27. Grzesik W. J. Integrins and bone--cell adhesion and beyond. Arch Immunol Ther Exp (Warsz). 1997; 45(4): 271-5.

28. Lee J. W., Juliano R. Mitogenic signal transduction by integrin- and growth factor receptor-mediated pathways. Mol Cells. 2004; 17(2): 188202.

29. Dudeck J., Rehberg S., Bernhardt R., Schneiders W., Zierau O., Inderchand M., et al. Increased bone remodelling around titanium implants coated with chondroitin sulfate in ovariectomized rats. Acta Biomater. 2014; 10(6): 2855-65.

30. Ruoslahti E., Yamaguchi Y. Proteoglycans as modulators of growth factor activities. Cell. 1991; 64(5): 867-9.

31. Bierbaum S., Douglas T., Hanke T., Scharnweber D., Tippelt S., Monsees T. K., Funk R. H., Worch H. Collageneous matrix coatings on titanium implants modified with decorin and chondroitin sulfate: characterization and influence on osteoblastic cells. J Biomed Mater Res A. 2006; 77(3): 55162.
32. Rammelt S., Illert T., Bierbaum S., Scharnweber D., Zwipp H., Schneiders W. Coating of titanium implants with collagen, RGD peptide and chondroitin sulfate. Biomaterials. 2006; 27(32): 5561-71.

33. Федоров В.Г. Импрессионные переломы костей нижних конечностей. Определение, классификация, тактика лечения. Книга 1. Ижевск; ОАО «Ижевская республиканская типография»; 2014.

34. Шелудченко О.С. Способ лечения повреждений опорно-двигательного аппарата, связанных с нарушением целостности кости, фармацевтический препарат для его осуществления и применение хондроитин сульфата для ускорения формирования фиброзно-хрящевой мозоли. Патент 2667468, РФ, 2018.

\section{References}

1. Alflutop (Alflutop $\left.{ }^{\circledR}\right)$. Available at: https://grls.rosminzdrav.ru/ Grls View v2.aspx?routingGuid=e8ad7e7f-98c1-4389-a6d6$1 \mathrm{fc} 8 \mathrm{c} 4 \mathrm{~cd} 969 \mathrm{a} \& \mathrm{t}$.

2. Voloshin VP, Saravanan SA, Eremin AV, et al. Study of chondrogard (chondroitin sulfate) efficacy in patients with fractures of different localization. Farmateka. 2016; 7: 76-9. (in Russian)

3. Vavilova TP. Biochemistry of tissues and oral fluids: A training manual. Chapter 5 Bone Biochemistry 2nd ed. [Biokhimiya tkaney i zhidkostey polostey rta: uchebnoe posobie. Glava 5 Biokhimiya kostnoy tkani 2 izd]; Moscow; GEOTAR-Media; 2008. (in Russian)

4. Peshehonova LK, Krasjukov PA, Peshehonov DV. Assessing the role of Alflutopus in osteoarthritis therapy: indications, clinical efficacy, tolerance and impact on quality of life. Meditsinskiy sovet. 2016; 11: 100-4. (in Russian)

5. Olariu L, Pyatigorskaya N, Dumitriu B, Manuela D, Pavlov A, Rosoiu N. Alflutop ${ }^{\circledR m o d u l a t e s ~ " i n ~ v i t r o " ~ r e l e v a n t ~ m e c h a n i s m s ~ o f ~ o s t e o a r t h r i t i c ~}$ pathology. Academy of Romanian ScientistsAnnals Series on BiologicalSciences. 2017; 6(1): 82-99.

6. 6.McAlindon T.E., LaValley M.P., Gulin J.P., Felson D.T. Glucosamine and chondroitin for treatment of osteoarthritis: a systematic quality assessment and meta-analysis. Jama. 2000; 283(11): 1469-75.

7. Martel' I.I. Abrupt osteosynthesis by Ilizarov in the complex treatment of patients with open limb injuries. Geniy ortopedii. 2011; 2: 44-8. (in Russian)

8. Miromanov A.M., Gerasimov A.A., Namokonov E.V., Miromanova N.A. Prediction of purulent-inflammatory complications in open fractures of long tubular bones. Vestnik khirurgii im. I.I. Grekova. 2009; 168(3): 5760. (in Russian)

9. Kluchevskiy V.V., Solov'yov I.N., Litvinov I.I., Timushev A.A. Treatment of open tibia fractures. Vrach-aspirant. 2015; 68(1.1): 199-03. (in Russian)

10. Kavalerskiy G.M., Petrov N.V., Brovkin S.V., Smirnov A.E., Kalashnik A.D., Karev A.S., et al. On the issue of treating open tibia fractures. Moskovskiy khirurgicheskiy zhurnal. 2014; 6: 33-6. (in Russian)

11. Mathavan N., Tägil M., Isaksson H. Do osteoporotic fractures constitute a greater recalcitrant challenge for skeletal regeneration? Investigating the efficacy of BMP-7 and zoledronate treatment of diaphyseal fractures in an open fracture osteoporotic rat model. Osteoporosis international: a journal established as result of cooperation between the European Foundation for Osteoporosis and the National Osteoporosis Foundation of the USA. 2017; 28(2): 697-07.

12. Mihanov V.A., Polyakova V.S., Kopylov V.A., Mhitaryan E.E. Reparative bone histogenesis in open fracture of long bone diaphysis in rats using "WINFAR”. Sovremennye problemy nauki i obrazovaniya. 2015; 3: 162. (in Russian)

13. Kopylov V.A., Safronov A.A., Zakharov V.V. Stimulation of reparative osteogenesis in the treat-ment of open fractures using metabolites of bacillus subtilis 804 containing the fibroblast growth factor. Wschodnioeuropejskie Czasopismo Naukowe (East European Scientific Journal). 2016; 9: 72-9. (in Russian)

14. Penn-Barwell J.G., Baker B., Wenke J.C. Local bismuth thiols potentiate antibiotics and reduce infection in a contaminated open fracture model. $J$ Orthop Trauma. 2015; 29(2): e73-8.

15. Mills R., Cheng T.L., Mikulec K., Peacock L., Isaacs D., Genberg C., et al. CSA-90 Promotes Bone Formation and Mitigates Methicillin-resistant Staphylococcus aureus Infection in a Rat Open Fracture Model. Clinical orthopaedics and related research. 2018; 476(6): 1311-23. 
16. Frost H.M. The biology of fracture healing. An overview for clinicians. Part I. Clin Orthop Relat Res. 1989; 248: 283-93.

17. Currey J.A., Mancuso M., Kalikoff S., Miller E., Day S. Controlled cyclic compression of an open tibial fracture using an external fixator affects fracture healing in mice. J Biomech Eng. 2015; 137(5): 051011.

18. Metineren H, Dulgeroglu TC, Metineren MH, Aydin E. Effect of nebivolol on fracture healing: An experimental rat model. Advances in clinical and experimental medicine: official organ Wroclaw Medical University. 2017; 26(6): 919-23.

19. Anesthesia and Analgesia in Laboratory Animals at UCSF. The Regents of the University of California. Available at: http://www.iacuc.ucsf.edu/Proc/ awRbtFrm.asp.

20. Warden SJ, Komatsu DE, Rydberg J, Bond JL, Hassett SM. Recombinant human parathyroid hormone (PTH 1-34) and low-intensity pulsed ultrasound have contrasting additive effects during fracture healing. Bone. 2009; 44(3): 485-94.

21. Magrupov B.A., Shadmanov T.T., Tashpulatov A.A., Hodzhaev R.R., Valiev E.Yu. Response of bone tissue to some implants in the experiment. Morfologiya. 2012; VI(2): 19-28. (in Russian)

22. Volotovskiy A.I., Makarevich E.R., Chirak V.Y. Bone regeneration in normal and pathological conditions: guidelines. Minsk; BGMU; 2010. (in Russian)

23. Garcia P, Histing T, Holstein JH, et al. Rodent animal models of delayed bone healing and non-union formation: a comprehensive review. European cells \& materials. 2013; 26: 1-12; discussion 12-14.

24. Olariu L, Pyatigorskaya N, Dumitriu B. "In vitro" chondro-restitutive capacity of Alflutop ${ }^{\circledR}$ proved on chondrocytes cultures. Romanian Biotechnological Letters. 2016; 22(6): 12047-53.

25. Chichasova N.V. Modern osteoarthritis therapy. Meditsinskiy sovet. 2017; 17: 138-45. (in Russian)

26. Sasaki T, Watanabe C. Stimulation of osteoinduction in bone wound healing by high-molecular hyaluronic acid. Bone. 1995; 16(1): 9-15.
27. Grzesik W.J. Integrins and bone-cell adhesion and beyond. Arch Immunol Ther Exp (Warsz). 1997; 45(4): 271-5.

28. Lee J.W., Juliano R. Mitogenic signal transduction by integrin- and growth factor receptor-mediated pathways. Mol Cells. 2004; 17(2): 188-202.

29. Dudeck J., Rehberg S., Bernhardt R., Schneiders W., Zierau O., Inderchand M., Goebbels J., Vollmer G., Fratzl P., Scharnweber D., Rammelt S. Increased bone remodelling around titanium implants coated with chondroitin sulfate in ovariectomized rats. Acta Biomater. 2014; 10(6): 285565.

30. Ruoslahti E., Yamaguchi Y. Proteoglycans as modulators of growth factor activities. Cell. 1991; 64(5): 867-9.

31. Bierbaum S., Douglas T., Hanke T., Scharnweber D., Tippelt S., Monsees T. K.et al. Collageneous matrix coatings on titanium implants modified with decorin and chondroitin sulfate: characterization and influence on osteoblastic cells. J Biomed Mater Res A. 2006; 77(3): 551-62.

32. Rammelt S., Illert T., Bierbaum S., Scharnweber D., Zwipp H., Schneiders W. Coating of titanium implants with collagen, RGD peptide and chondroitin sulfate. Biomaterials. 2006; 27(32): 5561-71.

33. Fedorov V.G. Impressionnee fractures of the lower extremities. Definition, classification, therapeutic approach. Book 1. [Impressionnye perelomy kostey nizhnikh konechnostey. Opredelenie, klassifikatsiya, taktika lecheniya. Kniga 1]. Izhevsk: OAO «Izhevskaya respublikanskaya tipografiya»; 2014. (in Russian)

34. Sheludchenko O.S. Method for treating damage of musculoskeletal system related to solution of continuity, pharmaceutical medication for its implementation and use of chondroitin sulfate for accelerating formation of fibrocartilagenous callus. [Sposob lecheniya povrezhdeniy oporno-dvigatel'nogo apparata, svyazannykh s narusheniem tselostnosti kosti, farmatsevticheskiy preparat dlya ego osushchestvleniya i primenenie hondroitin sul'fata dlya uskoreniya formirovaniya fibrozno-hryashchevoy mozoli. Patent 2667468]. RF, 2018. (in Russian)

\section{Сведения об авторах:}

Куксгауз Илона Александровна, фармаколог отдела экспериментальной фармакологии и токсикологии;

Кашкин Владимир Александрович, канд. мед. наук, ст. науч. сотр., отдел экспериментальной фармакологии, е-таil: kashkinv@gmail.com;

Шекунова Елена Васильевна, канд. биол. наук, руководитель отдела экспериментальной фармакологии и токсикологии;

Гущин Ярослав Александрович, руководитель отдела гистологии и патоморфологии;

Макарова Марина Николаевна, доктор мед. наук, заместитель директора по науке;

Макаров Валерий Геннадьевич, доктор мед. наук, проф., директор, ЗАО «Санкт-Петербургский институт фармации». 